\title{
WITHOUT A CONFLICT MODEL OF ELECTRON
}

\author{
Vasil Tchaban* \\ Lviv Polytechnic National University, Lviv, Ukraine
}

(Received December 22, 2017)

\begin{abstract}
The model of electron is offered with quark distribution of charge density and "white hole" (on similarity of "black hole" in gravitation) in a center. Such structure abolishes the crisis of electromagnetic mass, calculated on universal formula and on the impulse of the electromagnetic field. A model in order to please a classic electrodynamics keeps monolithic nature of elementary particle, and in order to please a quantum allows the separate charged zones to interpret as separate quarks. Coming from harmony of spheres of the separate charged zones, a white hole can be interpreted as white (neutral) quark conditionally in addition to three coloured. As after the electric radius $r_{e}=1.185246 \cdot 10^{-15} \mathrm{~m}$ of white hole the laws of electricity do not operate, then the crisis of point charge is removed at the same time too, because of must be: $r \geq r_{e}$.
\end{abstract}

PACS: 11.25.-w, 12.60.Jv, 02.10.Ws

\section{INTRODUCTION}

Unfortunately until now the theory of the electromagnetic field does not have a trouble-free model of the own simplest charged elementary particle - of electron. Self-contradictions of the known constructions are taken two problems.

The first from them is related to the paradox of self-acting of electron on itself. Its essence consists in that the electromagnetic mass of movable electron $m_{e}$, got through the impulse of the electromagnetic field, appears less than the mass of rest. Up the decision of this problem the lightest minds of creators of theoretical physics took at one. But all their results in any case, but required of intervention in fundamental equations of electromagnetism and even complete abandonment from electromagnetic mass [1]. Only Poincare as a temporal exit from a situation offered self-acting of electron on itself which are the so-called "Poincare's springs". Exactly energy of these magic springs targeted at com-pensation of necessary deficit of mass. But years passed, and nobody so found out these springs. The second problem is related to boundless energy and in concert by mass of point charge at aspiration of radius of particle to the zero.

Speech will go in this article about both problems and about consequences that arise up as a result of overcoming of them. Both they are a substantial obstacle to understanding of fundamental essence of electricity. From the point of view to meaningfulness them for a theory we consider necessary to say and own opinion that does not apply on final truth, but has a right on existence, as well as known. Beginning to bustle in advance, we will say, that it no way enters into a dispute neither with the modern theory of electricity nor with an experiment, and contrary, appears on their background.
Historically all was begun with the paradox of electromagnetic mass of electron. About itself will say in beginning: we belong to those, who divides the idea of Lorenz that mass of electron can be fully electro-magnetic (all its $0.511 \mathrm{MeV}$ ), and a charge is not a point, and "sloping", as accepted to talk in physics.

\section{IMPULSE OF MOVABLE ELECTRON}

Electron is a stable, negatively charged elementary particle that enters in the structure of all atoms $\left(-e=-1.6021892(46) \cdot 10^{-19} C\right.$, $\left.m_{e}=9.109554(906) \cdot 10^{-31} \mathrm{~kg}\right)$. Time of life of it is $10^{26}$ over. By stability, thanks you to the law of conservation of electric charge. An anti-particle is a positron. Mass of electron can be easily calculated by his impulse for velocities $v \ll c[1]$. The density of impulse $\vec{g}$ of the electromagnetic field we will find dividing the vector of Pointing $\vec{\Pi}=\varepsilon_{0} c^{2} \vec{E} \times \vec{B}$ by $c^{2}$

$$
\vec{g}=\varepsilon_{0} \vec{E} \times \vec{B}
$$

where $\vec{E}, \vec{B}$ are basic vectors of the electromagnetic field, $\varepsilon_{0}$ is an electric constant, $c$ is speed of light.

An electron will examine as the charged sphere with a radius $a$ but also charge $q$ that moves with permanent velocity $\vec{v}$. In some point that is in the distance $r$ from the center of charge and under a corner $\Theta$ to the line of his motion, electric field is radial, and the lines of force of magnetic field appear as circles round the line of motion [1]

$$
\vec{B}=\frac{\vec{v} \times \vec{E}}{c^{2}}
$$

Putting (2) in (1), we receive a value (1)

$$
g=\frac{\varepsilon_{0} v}{c^{2}} E^{2} \sin \Theta .
$$

*Corresponding author E-mail address: vtchaban@polynet.lviv.ua 
The field is symmetric to the line of motion of charge that is why transversal components give a zero in a sum. As a result an impulse will be parallel to the rate of movement $(\vec{v})$. The component of vector $g$ in this direction $g \sin \Theta$ can integrate about all space. As an element of volume we will take a ring which the plane is perpendicular to the vector $\vec{v}$. An elementary volume of such ring will be as $d V=2 \pi r^{2} \sin \Theta d \Theta d r$. Then a complete impulse takes look

$$
\vec{p}=\int_{a}^{\infty} \int_{0}^{\pi} \frac{\varepsilon_{0} \vec{v}}{c^{2}} E^{2} \sin ^{3} \Theta 2 \pi r^{2} d \Theta d r .
$$

Coming from spherical symmetry, the size of electric field we will find by the Maxwell's postulate

$$
E=\frac{q}{4 \pi \varepsilon_{0} r^{2}}
$$

According to (4), (5) we get finally

$$
\vec{p}=\frac{2}{3} \frac{\alpha^{2}}{a c^{2}} \vec{v}, \quad \alpha^{2}=\frac{q^{2}}{4 \pi \varepsilon_{0}} .
$$

Coefficient of proportion between an impulse and a speed in (6) is electromagnetic mass of electron

$$
m_{e}=\frac{2}{3} \frac{\alpha^{2}}{a c^{2}}
$$

\section{ELECTROMAGNETIC MASS}

In relation to truth of expression (6) of differences in opinion for physicists it is not. But problem in other - in deviation from (6) mass of immobile particle, received from universal expression $m_{e}=W / c^{2}$, where $W$ is energy. Specific electric energy $w$ of immobile electron it easily to calculate according to the known expression

$$
w=\frac{\varepsilon_{0}}{2} E^{2} .
$$

If to consider that a charge of particle is on its spherical surface, then we find complete energy according to volume integral

$$
W=\frac{\varepsilon_{0}}{2} \int_{a}^{\infty} 4 \pi E^{2} r^{2} d r .
$$

Putting (5), (8) in (9), we get

$$
W=\frac{1}{2} \frac{\alpha^{2}}{a} .
$$

Dividing (10) by $c^{2}$, we get mass of rest

$$
m_{e}^{\prime}=\frac{1}{2} \frac{\alpha^{2}}{a c^{2}}
$$

As we have an obvious deficit of mass as compared to (7), then logically to accept, that charge of particle evenly "sloping" for it the body that will bring in internal energy of particle in consideration. Expression for the vector of tension of electric field at that rate find by the Maxwell's postulate too

$$
E-\frac{q}{4 \pi \varepsilon_{0} a^{3}} r .
$$

It is experimentally confirmed within 15 millionth, that coefficient that appears in (12), on distances $10^{-10} \mathrm{~m}$ remains to the same. In classic physics his truth confesses and on distances $10^{-15} \mathrm{~m}$. is in relation to the conclusion (5) of warning, because does not cross the limit of distances $10^{-15} \mathrm{~m}$. And in relation to (12) they are, because as a result of bombardment of protons by rapid electrons according to their dispersion is set, that on distances a $10^{-16} \mathrm{~m}$ the law of Coulomb does not operate! On founding (9), (12) on condition of change of borders of integration scope from 0 to $a$ we obsessed, that

$$
m_{e}^{\prime \prime}=\frac{1}{10} \frac{\alpha^{2}}{a c^{2}} .
$$

Adding (11) and (13), we obsessed finally

$$
m_{e}=\frac{3}{5} \frac{\alpha^{2}}{a c^{2}}
$$

As see, the deficit of mass is farther present. Deficit of mass between (7) and (14), as it was already said before, on the first pores Henry Poincare proposed to recompense by self-acting of electron on itself. This action conditionally until is named as "intensities" or "springs" of Poincare. Clear, that nature there is not solved!

In relation to the presence of "springs" of Poincare of dispute conducted until now. A basic argument on their benefit is that, what an accelerated electron radiates energy. But in that there is chicanery a ground. Electron can not be accelerated without assistance. Here must be added external force. It undertakes all "charges". Interestingly, that in an own idea to decide a problem Feynman ladles this additional force in interplaying of oscillating electron with all by other charges in the world by means of passing ahead and delayed waves, and "radiation resistance in no way arises up as a result of self-acting". Understanding a situation well, he finally acknowledges: "Here physicists are tangled in what loop (!)".

Our idea is very simple. Keeping within the law of classic electrodynamics, to reconcile with both masses (7) and (14) in behalf on first from them. For that we renounce a concept a point charge, and consider the real up-diffused on the volume of active zone, but not evenly, as accepted in a classic electrodynamics, and unevenly!

\section{MODEL OF ELECTRON}

The experimental fact of collapse of law of Coulomb on distances a $10^{-16} \mathrm{~m}$ talks about one - after the sphere of radius in neighborhood of such sizes the electric field is absent, and it will be only then, when its charges will not be able to step over. Thus, there is electric emptiness that conditionally will name a "white hole". Certainly, about the laws of electromagnetism in such emptiness, talking will not be. Fully reasonably to search the radius of such white hole exactly in the elementary charge of the least sizes, that is an electron. In gravitation too similar 
is a "black hole", or sphere of Schwarzshild. A physical body after this sphere too tests a gravitational collapse. So as a radius of sphere of Schwarzshild $r_{g}$ is named gravitational, then we the radius $r_{e}$ of our sphere will name like - electric. For a typical neutron star a gravitational radius presents about $1 / 3$ from its own radius. It is therefore possible to expect that an electric radius too will be multiple $1 / 3$ from an own radius.

Divergence of expressions (7) and (14) proves simply, that a density of electric charge must be updiffused on the volume of particle unevenly. We have a few reasonable variants of this unevenness, but here will show the simplest, and at the same time most reliable from them - quark distribution.

Quarks were thought in 1964 by Hell-Mann and independently by Zweig for explanation of symmetry in properties of strongly interactive particles hadrons. An electron after imagination of quantum physics consists of three quarks that own an electric charge multiple $e / 3$. This repetition factor meets in physics often enough, for example, the relation of magnetic moments of neutron and proton equals $-2 / 3$, super proton and proton $--1 / 3$ and others like that. Indeed, as an electric radius of electron will be shown farther presents about $2 / 3$ from its own actual radius and. Why actual? - Because conditional $r_{0}=2.82 \cdot 10^{-15} \mathrm{~m}$ from the vagueness of digital coefficients in (7) and (14), gravitating to (7), for the real the masses of $m_{e}$ and charge of $e$ overpriced in $3 / 2$ times.

There are written about quarks differently. Experimenters consider them as structure less body, point, that "tested up to $5 \cdot 10^{-18} \mathrm{~m}$ ". A quantum chromo dynamics considers that a "colorless" electron consists of three "coloured" quarks (red, yellow, blue), and each of two has them charges $-e 2 / 3$ and one quark of the third color $-+e 1 / 3$. But is and candid: "In this time any experimental or theoretical ideas are absent in relation to distribution of quarks in the volume of electron... From this point of view a hypothesis about an electron as a sphere is simpler in all and most acceptable [1]".

We do not examine an electron as quark structure. We only will accept quark distribution of densities of charge in three active zones of identical volume along of radius $r$ : $-e 2 / 3,-e 2 / 3,+e 1 / 3$. Thus, such their sequence is certain a condition (7)! It even something simplifies an analysis, because two zones give an opportunity of the first to unite in one. In separate zones charge densities are considered permanent. Such model of electron is or not only, that touch not of interests of neither classic nor quantum electrodynamics. Because in order to please classic keeps monolithic nature of elementary particle, and in order to please a quantum interprets the separate charged zones as separate discrete quarks.

At of such structure of active zones and presence in the center of white hole with a radius $r_{e}$ internal energy of the charged hollow bullet can be easily found after according to the postulate of Maxwell, as a sum of energies of its separate zones (it is specified comparatively with [2]):

$$
\begin{aligned}
w_{e i}(\xi)= & \frac{\alpha^{2}}{2 a}\left(\frac{m_{1}^{2}}{4 b^{2}}\left(\frac{k_{r 2}^{5}-\xi^{5}}{5}\right)-\xi^{3}\left(k_{r 2}^{2}-\xi^{2}\right)+\right. \\
& +\xi^{6}\left(\frac{1}{\xi}-\frac{1}{k_{r 2}}\right)+\frac{m_{2}^{2}}{b^{2}} \frac{1-k_{r 2}^{5}}{5}- \\
- & \left(\frac{m_{1} m_{2}}{b}+\frac{m_{2}^{2}}{b^{2}} k_{r 2}^{3}\right)\left(1-k_{r 2}^{2}\right)+ \\
& \left.+\left(\frac{m_{2}^{2}}{b^{2}} k_{r 2}^{6}+\frac{2 m_{1} m_{2}}{b}+m_{1}^{2}\right)\left(\frac{1}{k_{r 2}}-1\right)\right),
\end{aligned}
$$

where: $\quad m_{1}=-4 / 3 ; \quad m_{2}=+1 / 3 ; \quad r_{e}=\xi a ; \quad r_{1}=k_{1} a$; $r_{2}=k_{2} a$ are external radiuses of white hole first and second active zones; find other coefficients, coming from the condition of equality of volumes of separate active zones: $k_{1}=\sqrt[3]{\left(1+2 \xi^{3}\right) / 3} ; k_{2}=\sqrt[3]{\left(2+\xi^{3}\right) / 3} ; b=\left(1-\xi^{3}\right) / 3$.

Only single value that answers to condition (7) we find as a solving of such nonlinear equation

$$
w_{e i}(\xi)=\frac{\alpha^{2}}{6 a}
$$

As of result $\xi=0.62996 \approx 0.63$, what is, as well as it was expectantly in neighbourhood $2 / 3$ with divergence $5 \%$.

Now attention! It is a rare case in science, when the solution of difficult physical equation turns out without the use of mathematical vehicle, and only coming from striking harmony of external spheres of while hole and all three active zones [2-4]:

$$
\begin{array}{ccc}
\hline=0.6300 & r_{e}=\sqrt[3]{1 / 4} a \\
k_{1}=0.7937 & r_{1}=\sqrt[3]{2 / 4} a \\
k_{2}=0.9087 & r_{1}=\sqrt[3]{3 / 4} a \\
1 & r_{1}=\sqrt[3]{4 / 4} a \\
\hline
\end{array}
$$

Will quote the same Poincare [5]: "That we name objective reality, finally ... there can be only harmony that is expressed by mathematical; laws. Thus, exactly this harmony and there is only objective reality, only truth that we can attain; and if will add, that universal harmony of the world is source of every beauty, then it will be understood, how we must value those slow and heavy steps forward, that little by little discover its to us".

Putting a numerical value $\xi$ in (15) and dividing the got result by $c^{2}$, we received the mass of electron, caused by its internal electric energy

$$
m_{e i}=\frac{1}{6} \frac{\alpha^{2}}{a c^{2}} .
$$

Mass $m_{e}^{\prime}$ that appears in (11) predefined by external electric energy of electron. It follows out from the limits of integration: $a \leq r \leq \infty$.

Adding the got masses of electron (11) and (17)

$$
m_{e}=\frac{1}{2} \frac{\alpha^{2}}{a c^{2}}+\frac{1}{6} \frac{\alpha^{2}}{a c^{2}}=\frac{2}{3} \frac{\alpha^{2}}{a c^{2}},
$$

we get a result that identically converges from (7). That it this, what was necessary to prove. 
As both masses are equal now, then for the veritable radius of electron it is possible to take its natural value $a$.

We will consider that the laws of electricity are deprived sense into a "white hole" with the radius $r_{e}=1.183487 \cdot 10^{-15} \mathrm{~m}$ as electric charges can not penetrate for its. It is a very important conclusion, because it abolishes the duty problem of boundless energy (5) at $r=0$, and in concert the masses (7) point charge at $a=0$. Because according to (16) neither $r$ nor $a$ can not step over the boundary of radius of "white hole". Harmony of external spheres of white hole and all three active zones strikes [2-4]:

If to examine such structure of electron as quark, then coming from this harmony, a white hole can be interpreted as fourth white (neutral) quark. But at that rate for the sake of presence of orbital moments we will not to forbid for our quarks to be revolved one in relation to other.

The results of simulation are shown in Figure.

The offered model of electron abolishes two important problems of electricity at least, not entering into contradiction with its classic laws. About other elementary charged particles and about quarks speech will go separately.

Interestingly, that J. Zweig named quarks as aces, but such name did not get accustomed, because aces were four, but quarks there were three in a primary model. Maybe our white and is that fourth ace (?).

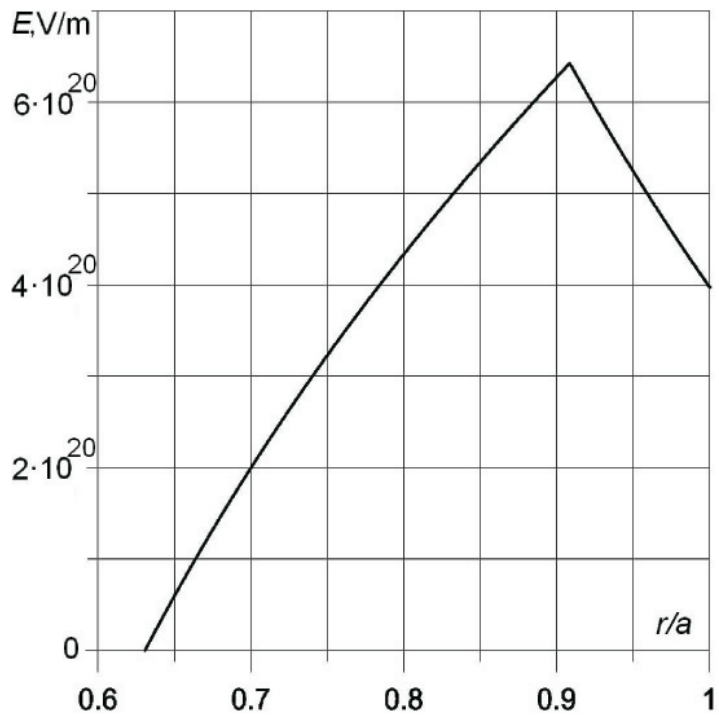

Distribution of intensity of electric field into an electron by the radius

Interestingly, that on this theme discussions are conducted in the Internet [3], where the paradox of the masses got even the proper name as "Paradox 4/3" [6]. It once again convinces about importance of these scientific efforts. In this connection it is necessary to mark that quark distribution of charge of electron is offered with a white hole in a center does not exhaust possibilities offered approach. Here a basic idea consists in uneven distribution of charge for volume of elementary particle. But offered as yet most aesthetic. And yet. We executed calculations for $v \ll c$. But a problem remains at relativistic speeds, as a formula (6) takes away with itself the same problem fully [1]

$$
\vec{p}=\frac{2}{3} \frac{\alpha^{2}}{a c^{2}} \frac{\vec{v}}{\sqrt{1-v^{2} / c^{2}}} .
$$

In other words, electromagnetic mass too grows with speed inversely proportional to the multiplier of Lorenz.

\section{CONCLUSIONS}

1. In order to avoid the crisis of electromagnetic mass of electron, we must give up the "Poincare's springs" and even distribution of densities of charge in its body in behalf on uneven, and also from existence of point charges in behalf on hollow.

2. If to take such proposed structure as quark structure, then a white hole can be interpreted as white quark (?) in addition to red, yellow and blue.

3 . The solution of nonlinear power equation of electron of 6 -th order on a miracle turns out in a round to the mathematical actions, going only from harmony of outerspheres of "quark" zones.

4. Even if to fill the body of electron by three spherical quarks, then nevertheless a white hole in a center not to avoid.

\section{References}

1. Р. Фейнман, Р.Лейтон, М.Сэндс. Фейнмановские лекции по физике, т.6. Москва: "Мир", 1977.

2. В. Чабан. Гіпотеза про електричні білі діри // Texнічні вісті (Technical news). 2015, т.1(41), т.2(42), c.9-10.

3. В. Чабан. Електромагнітні процеси. Л.: "Простір", 2017, 412c.

4. Я.Буджак, В. Чабан. Енергетичні та кінетичні властивості напівпровідникових кристалів. Л.: "Простір", 2017, 190c.

5. А. Пуанкаре. О науке. М.: "Мир", 1983, 560с.

6. STO KED Paradox $4 / 3$ forum. forum. lebedev.ru/vievtopic.php?t=2717 


\section{БЕСКОНФЛИКТНАЯ МОДЕЛЬ ЭЛЕКТРОНА}

\section{Василий Чабан}

Предложена модель электрона с кварковым распределением плотности заряда и "белой дырой"(на подобие "черной дыры"в гравитации) в центре. Такая структура устраняет кризис электромагнитной массы, вычисленной по универсальной формуле энергии и через импульс электромагнитного поля. Модель на удовлетворение классической электродинамике сохраняет монолитность элементарной частицы, а на удовлетворение квантовой - разрешает отдельные заряженные зоны рассматривать как отдельные кварки. Исходя из гармонии сфер отдельных заряженных зон, "белую дыру"можно условно рассматривать как белый (нейтральный) кварк в дополнение до трех цветных (?). Поскольку за электрическим радиусом "белой дыры" $r_{e}=1,185246 \cdot 10^{-15} \mathrm{~m}$ законы электричества не действуют, то одновременно устраняется кризис точковости заряда, как недействительного, ибо должно быть $r \geq r_{e}$.

\section{БЕЗКОНФЛІКТНА МОДЕЛЬ ЕЛЕКТРОНА}

\section{Василь Чабан}

Запропоновано модель електрона з кварковим розподілом густини заряду й "білою дірою"(на подобу "чорної діри"в гравітації) у центрі. Така структура скасовує кризу електромагнітної маси, обчисленої за універсальною формулою енергії і за імпульсом електромагнітного поля. Модель на догоду класичній електродинаміці зберігає монолітність елементарної частинки, а на догоду квантовій - дозволяє окремі заряджені зони трактувати як окремі кварки. Виходячи з гармонії сфер окремих заряджених зон, "білу діру"можна умовно трактувати як білий (нейтральний) кварк на додаток до трьох кольорових (?). Оскільки за електричним радіусом "білої діри" $r_{e}=1,185246 \cdot 10^{-15} \mathrm{~m}$ закони електрики не діють, то водночас знімається криза точкового заряду, як нереального, бо мусить бути $r \geq r_{e}$. 